\title{
Effect of thermal annealing on the blue luminescence of amorphous silicon oxycarbide films
}

\author{
Zhenxu Lin $^{\text {a), b) }}$, Yanqing Guo ${ }^{\text {a),*, Jie Song }}{ }^{\text {a) }}$, Yi Zhang ${ }^{\text {a), b) }}$, Chao Song ${ }^{\text {a) }}$, Xiang \\ Wang $^{\text {a) }}$, and Rui Huang ${ }^{\text {a) }}$
}

a) Department of Physics and Electronic Engineering, Hanshan Normal University, Chaozhou, Guangdong 521041, China

b) Institute of Nanoscience and Nanotechnology, Central China Normal University, Wuhan 430079, China

*yqguo126@126.com

\begin{abstract}
Amorphous silicon oxycarbide $\left(\mathrm{a}-\mathrm{SiC}_{\mathrm{x}} \mathrm{O}_{\mathrm{y}}\right)$ films that displayed blue luminescence were fabricated using very high frequency plasma-enhanced chemical vapor deposition (VHF-PECVD) at a temperature of $250{ }^{\circ} \mathrm{C}$. The effects of thermal annealing on the photoluminescence (PL) were investigated. Thermal annealing at $600{ }^{\circ} \mathrm{C}$ resulted in a remarkable enhancement in the blue PL, which was clearly observed with the naked eyes in a bright room. The blue PL featured an excitation wavelength independent recombination dynamic on a nanosecond timescale. Neither $\mathrm{Si}$ nor $\mathrm{SiC}$ quantum dots were present in the annealed films as revealed by transmission electron microscopy. The PL results, combined with an analysis of the chemical bonds present in the films, revealed the origin of the blue PL was largely due to electron-hole pair recombination through Si-related neutral oxygen vacancy defect centers.
\end{abstract}

Keywords: silicon oxycarbide, photoluminescence, PECVD 


\section{Introduction}

Silicon-based light-emitting materials have attracted attention over the past decade for their potential as next-generation Si photonics. Silicon-based materials, including silicon nitride $\left(\mathrm{SiN}_{\mathrm{x}}\right)$ [1-3], silicon oxide $\left(\mathrm{SiO}_{\mathrm{x}}\right)$ [4-10], silicon oxynitride $\left(\mathrm{SiN}_{\mathrm{x}} \mathrm{O}_{\mathrm{y}}\right)$ [11-14], and silicon oxycarbide $\left(\mathrm{SiC}_{\mathrm{x}} \mathrm{O}_{\mathrm{y}}\right)$ [15-18], show promise as CMOS-compatible integrated light sources. Thus, significant research efforts have been devoted to understand and optimize their structural and optical properties. $\mathrm{SiC}_{\mathrm{x}} \mathrm{O}_{\mathrm{y}}$ generally features strong white light emission and is regarded as a promising host matrix for rare earth [16-20]. It has been reported that $\mathrm{SiC}_{\mathrm{x}} \mathrm{O}_{\mathrm{y}}$ is more effective at enhancing the mobility and solubility of $\mathrm{Eu}^{2+}$ ions than is $\mathrm{SiO}_{x}$, and thus significantly increases the PL intensity of $\mathrm{Eu}^{2+}[19]$. Furthermore, the effective excitation cross section of Er, in Er-doped amorphous $\mathrm{SiC}_{\mathrm{x}} \mathrm{O}_{\mathrm{y}}$, is four orders of magnitude larger than that when $\mathrm{Er}$ is excited directly. This is a result of energy transfer between the band edges or defect levels of $\mathrm{a}-\mathrm{SiC}_{\mathrm{x}} \mathrm{O}_{\mathrm{y}}$ and $\mathrm{Er}$ ions [20]. Efficient $\mathrm{PL}$ from $\mathrm{SiC}_{\mathrm{x}} \mathrm{O}_{\mathrm{y}}$ systems has been studied, although progress is slow. This is, in part because of a lack of information available to correlate the PL to other influences.

Previously, we reported that the strong light emission observed from a-SiC $\mathrm{O}_{\mathrm{y}}$ films can be tuned from yellow to blue by modulating the oxygen content in the films [21]. In the present work, the effect of thermal annealing on the blue luminescence of $\mathrm{a}-\mathrm{SiC}_{\mathrm{x}} \mathrm{O}_{\mathrm{y}}$ films was investigated. Thermal annealing at $600{ }^{\circ} \mathrm{C}$ was found to significantly enhance the blue PL. The PL featured a wavelength independent recombination dynamic on a nanosecond timescale. The origin of the blue PL was 
postulated by combining the PL results with an analysis of the microstructure and the chemical bonds within the films.

\section{Experimental}

a-SiC $\mathrm{X}_{\mathrm{y}}$ films with a thickness of $450 \mathrm{~nm}$ were prepared using VHF-PECVD with a gas mixture of $\mathrm{SiH}_{4}, \mathrm{CH}_{4}$, and $\mathrm{O}_{2}$ at flow rates of $2.5,10$, and $1.2 \mathrm{sccm}$, respectively. During the growth process, the radio frequency power, chamber pressure, and substrate temperature were $30 \mathrm{~W}, 20 \mathrm{~Pa}$, and $250{ }^{\circ} \mathrm{C}$ respectively. The detailed experiment was described in previous work [21]. The as-deposited samples were dehydrogenated at $400{ }^{\circ} \mathrm{C}$ for $1 \mathrm{~h}$. The samples were then annealed in a conventional furnace under a nitrogen atmosphere at 500,600 , or $700{ }^{\circ} \mathrm{C}$ for $1 \mathrm{~h}$. The PL measurements were performed at ambient temperature using a Jobin Yvon fluorolog-3 spectrophotometer equipped with a 450 W steady Xe lamp. PL time decay measurements were recorded using an Edinburgh FLS980 spectrometer. The band gaps of the samples were determined using optical absorption measurements performed on a Shimadzu UV-3600 spectrophotometer on quartz samples. The microstructures of samples were characterized using a JEOL high-resolution transmission electron microscope (TEM). The $\mathrm{Si}, \mathrm{O}$ and $\mathrm{C}$ elemental compositions within the samples were estimated using X-ray photoelectron spectroscopy (XPS). The local atomic environment and bonding configuration within the samples were recorded using Fourier transform infrared (FTIR) spectroscopy.

\section{Result and discussion}


The PL spectra of the as-deposited and annealed samples are shown in Fig. 1. The spectrum of the as-deposited sample displayed a broad band centered at approximately $475 \mathrm{~nm}$. This broad band can be deconvoluted into a strong blue Gaussian band and a weak orange Gaussian band. The integrated intensity and the full wide at half of maximum (FWHM) of the decomposed blue and orange Gaussian bands were summarized in Table I. From Fig. 1, one can see that the blue band was found to gradually shift from $475 \mathrm{~nm}$ to $420 \mathrm{~nm}$ as the annealing temperature was increased to $600{ }^{\circ} \mathrm{C}$. This blueshift was accompanied by a significant enhancement of the PL intensity. Thermal annealing of the films at $600{ }^{\circ} \mathrm{C}$ was found to significantly enhance the integrated PL intensity $\mathrm{I}_{\mathrm{PL}}$ of the blue PL by more than two times when compared with the as-deposited sample, as shown in Table I. Notably, the strong white light emission from the sample annealed at $600{ }^{\circ} \mathrm{C}$ could be clearly observed with the naked eye in a bright room when excited with a wavelength of $325 \mathrm{~nm}$ from Xe lamp, Fig. 1 (inset). However, as the annealing temperature was increased to $700{ }^{\circ} \mathrm{C}$, the intensity of blue PL dropped dramatically, while the orange band centered at approximately $625 \mathrm{~nm}$ become dominant. From Table I, one can also seen that the FWHM of the blue band decreased sharply with the increase of annealing temperature, while that of the orange band increased and saturated at the annealing temperature of $\underline{500}{ }^{\circ} \mathrm{C}:$

The optical band gap energies $\left(\mathrm{E}_{\mathrm{opt}}\right)$ of the samples were determined using the absorption profiles and the Tauc equation $(\alpha h v)^{1 / 2}=\mathrm{B}\left(h v-\mathrm{E}_{\mathrm{opt}}\right)$, where $\alpha$ is the absorption coefficient and $h v$ is the photon energy [22], Fig. 2 (inset). The energy of 
the PL peaks, and the corresponding $\mathrm{E}_{\mathrm{opt}}$ values, for the films annealed at different temperatures are shown in Fig. 2. From Fig.2, one can see that the behavior of the PL peak energy for both deconvoluted bands with the annealing temperature exhibit a similar tendency to the $\mathrm{E}_{\text {opt: }}$ The energy of the PL peak was lower than the corresponding $\mathrm{E}_{\mathrm{opt}}$ value, indicating that the PL of the samples did not originate from band to band recombination. This conclusion was supported by the absence of any Si or $\mathrm{SiC}$ nanocrystals within the sample annealed at $700{ }^{\circ} \mathrm{C}$, when observed using cross-sectional high-resolution TEM (Fig. 3). To understand the origins of PL emission, the samples were excited at different wavelengths, as displayed in Fig. 4. The PL peak position observed for all samples were independent of the excitation wavelengths. This PL behavior was similar to that of the defect-related PL in which the PL peak position is independent of the excitation wavelength because of a narrow distribution of defect-related localized states [23]. This result suggested that the PL may originate from defect-related luminescence centers.

To elucidate the nature of the blue light emission in the $\mathrm{a}-\mathrm{SiO}_{\mathrm{x}} \mathrm{C}_{\mathrm{y}}$ films, the PL lifetime of the samples were measured. The blue PL decay traces from the as-deposited and annealed samples are shown in Fig. 5. The decay traces fit the double exponential decay function:

$$
I(t)=I_{0}+I_{1} * \exp \left(-t / \tau_{1}\right)+I_{2} * \exp \left(-t / \tau_{2}\right)
$$

where $\mathrm{I}_{0}$ is the background level, $\mathrm{I}_{\mathrm{i}}$ and $\tau_{\mathrm{i}}(\mathrm{i}=1,2)$ are the amplitude and lifetime of each exponential decay component, respectively [23]. Fig. 5 shows that the blue luminescence lifetime $\tau$ of all samples contained both a fast decay component $\tau_{1}(1.27$ 
ns) and a long decay component $\tau_{2}$ (in the range of $6.53-5.48 \mathrm{~ns}$ depending on the annealing temperature). The dynamic behavior of the luminescence was consistent with that observed in defect-related $\mathrm{Si}$-based materials such as $\mathrm{SiN}_{\mathrm{x}} \mathrm{O}_{\mathrm{y}}$ and $\mathrm{SiO}_{\mathrm{x}}$, indicating the blue band observed in our samples originated from defect states. Additionally, the fast luminescence lifetimes $\tau_{1}$ determined for the samples were close to that reported by Pellegrino et al. and Nikas et al. where the PL was suggested to originate from C-related neutral oxygen vacancy (NOV) defect centers resulting from the weaker spin-orbit coupling strength of $C$ (lower atomic number) $[24,25]$. The longer luminescence lifetimes $\tau_{2}$ observed from the $\mathrm{a}-\mathrm{SiO}_{\mathrm{x}} \mathrm{C}_{\mathrm{y}}$ films were similar to that reported by Lin [26] where the PL was ascribed to NOV defect centers in amorphous $\mathrm{SiO}_{\mathrm{x}}$. Therefore, the blue light emission observed from a-SiO $\mathrm{C}_{\mathrm{y}}$ films may originate from C-related NOV defect centers and/or Si-related NOV defect centers.

FTIR absorption spectra for the samples are shown in Fig. 7. The spectrum of the as-deposited sample displayed distinct stretching modes at approximately 795 and $1020 \mathrm{~cm}^{-1}$ characteristic of Si-C and Si-O-Si bonds, respectively [27]. The shoulder on the high frequency side of the Si-O-Si mode (approximately $1260 \mathrm{~cm}^{-1}$ ) was attributed to $\mathrm{Si}-\mathrm{CH}_{3}$ stretching mode[27], while the bands at approximately $2160 \mathrm{~cm}^{-1}$ and $2950 \mathrm{~cm}^{-1}$ are characteristic of $\mathrm{Si}-\mathrm{H}$ and $\mathrm{C}-\mathrm{H}$ stretching modes, respectively [28, 29]. The intensity of the Si-O-Si bond stretching mode increased as the annealing temperature was increased. In contrast, the intensity of hydrogen-related absorption modes dropped as the annealing temperature was increased. The hydrogen-related 
absorption modes for the sample annealed at $700{ }^{\circ} \mathrm{C}$ diminished while the absorption peaks due to and Si-O-Si bonds became sharp and shifted to approximately $1040 \mathrm{~cm}^{-1}$. Additionally, a distinct absorption peak located at approximately $437 \mathrm{~cm}^{-1}$, characteristic of a Si-O-Si rocking mode, was observed [30]. These results indicated that the $\mathrm{Si}-\mathrm{H}$ bonds broke and transformed into $\mathrm{Si}-\mathrm{O}$ bonds after experiencing the high temperature annealing process. Compared Fig. 1 with Fig. 7, one can find that the intensity of the blue PL exhibits a similar tendency to the intensity of $\mathrm{Si}-\mathrm{O}-\mathrm{Si}$ bond stretching modes for the samples annealed below $700{ }^{\circ} \mathrm{C}$. Therefore, it is suggested that the increase of the blue emission intensity is closely related to the chemical bond reconstruction, particularly the increase in concentration of $\mathrm{Si}-\mathrm{O}$ $\underline{\text { bonds. }}$

XPS was used to probe the chemical environment of the $\mathrm{Si}, \mathrm{C}$ and $\mathrm{O}$ in the samples. The ratio of $\mathrm{Si}, \mathrm{C}$ and $\mathrm{O}$ in the as-deposited sample was found to be $30.28 \%$, $34.27 \%$, and $34.43 \%$, respectively. Thus, the dominant phase in the as-deposited sample was a C-rich $\mathrm{SiC}_{1.13} \mathrm{O}_{1.14}(\mathrm{SiC}$-like) phase. This suggested that oxygen defect centers, such as NOV, can be formed in C-rich $\mathrm{SiC}_{\mathrm{x}} \mathrm{O}_{\mathrm{y}}$ films due to a deviation from a perfect stoichiometry. The $\mathrm{C}$ content of the sample annealed at $500{ }^{\circ} \mathrm{C}$ decreased to $25.69 \%$, while the content of $\mathrm{Si}$ and $\mathrm{O}$ increased to $38.53 \%$ and $34.79 \%$, respectively. Therefore, the density of C-related NOV defect centers should decrease as a result of the lower C content. However, the PL intensity of the sample annealed at $500{ }^{\circ} \mathrm{C}$ increased significantly. This suggested that the blue light emission observed from the $\mathrm{a}-\mathrm{SiO}_{\mathrm{x}} \mathrm{C}_{\mathrm{y}}$ films originated mainly from Si-related NOV defect centers, which well 
explain the correlation observed between the PL intensity and Si-O-Si stretching mode with increasing annealing temperatures (below $700{ }^{\circ} \mathrm{C}$ ). We found that the dominant phase within the samples annealed at $700{ }^{\circ} \mathrm{C}$ became O-rich $\mathrm{SiC}_{0.42} \mathrm{O}_{1.33}$ ( $\mathrm{SiO}_{2}$-like) due to the elimination of $\mathrm{C}$ atoms [31]. This was also confirmed by FTIR spectroscopy as the peaks for the Si-O-Si bond stretching modes increased in intensity and displayed a blueshift. The $\mathrm{SiO}_{2} \underline{\text {-like sample exhibited weak orange light emission }}$

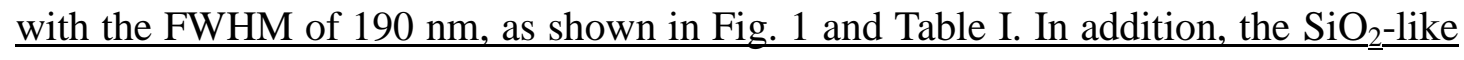
sample featured a fast decay dynamic with nanosecond lifetimes, as revealed in Fig. 7. Thus, combining with the work of Skuja et al. [32], the orange band were temporarily ascribed to non-bridging oxygen hole centers in silicon oxide.

\section{Conclusion}

In summary, the effect of thermal annealing on the blue $\mathrm{PL}$ of $\mathrm{a}-\mathrm{SiC}_{\mathrm{x}} \mathrm{O}_{\mathrm{y}}$ films has been investigated. Thermal annealing of the films was found to significantly enhance the intensity of the blue PL by more than four times when compared with the as-deposited sample. The blue PL featured an excitation wavelength independent recombination dynamic on a nanosecond timescale. Using a combination of PL experiments, cross-sectional high-resolution TEM and an analysis of the chemical bonds within the films, the origin of blue emission was found to be from radiative recombination through Si-related NOVs defect centers.

\section{Acknowledgments}

This work was supported by National Natural Science Foundation of China (Nos. 
61274140 and 61306003).

\section{References}

[1] L. Pavesi, L. Dal Negro, C. Mazzoleni, G. Franzo, F. Priolo, Optical gain in silicon nanocrystals, Nature. 408 (2000) 440-444.

[2] G. R. Lin, C. K. Lin, L. J. Chou, Y. L. Chueh, Synthesis of Si nanopyramids at $\mathrm{SiO}_{\mathrm{x}} / \mathrm{Si}$ interface for enhancing electroluminescence of Si-rich $\mathrm{SiO}_{\mathrm{x}}$, Appl. Phys. Lett. 89 (2006) 093126-093126-3.

[3] D. Chen, Y. Liu, J. Xu, D. Wei, H. Sun, L. Xu, T. Wang, W. Li, K. Chen, Improved emission efficiency of electroluminescent device containing $\mathrm{nc}-\mathrm{Si} / \mathrm{SiO}_{2}$ multilayers by using nano-patterned substrate, Opt. Express. 18 (2010) 917-922.

[4] K. Chen, X. Huang, J. Xu, D. Feng, Visible photoluminescence in crystallized amorphous Si:H/SiN $: H$ multiquantum-well structures, Appl. Phys. Lett. 61 (1992) 2069-2071.

[5] N. M. Park, C. J. Choi, T. Y. Seong, S. J. Park. Quantum confinement in amorphous silicon quantum dots embedded in silicon nitride, Phys. Rev. Lett. 86 (2001) 1355-1357.

[6] L. Dal Negro, J. H. Yi, L. C. Kimerling, S. Hamel, A. Williamson, G. Galli, Light emission from silicon-rich nitride nanostructures, Appl. Phys. Lett. 88 (2006) 183103 $-183103-3$.

[7] R. Huang, J. Song, X. Wang, Y. Q. Guo, C. Song, Z. H. Zheng, X. L. Wu, and P. K. Chu, Origin of strong white electroluminescence from dense Si nanodots embedded in 
silicon nitride, Opt. Lett. 37 (2012) 692-694.

[8]F. Wang, D. Li, D. Yang, Q. Que, Tailoring effect of enhanced local electric field from metal nanoparticles on electroluminescence of silicon-rich silicon nitride, IEEE J Sel. Topics Quantum. Electron. 19 (2013) 4602504.

[9] C Liu, C Li, A Ji, L Ma, Y Wang, Z Cao, Exploring extreme particle density and size for blue photoluminescence from as-deposited amorphous Si-in-SiN ${ }_{x}$ films, Appl. Phys. Lett. 22 (2005) 223111-223111-3.

[10] R. Huang, Z. Lin, Z. Lin, C. Song, Y. Guo, X. Wang, J. Song, Suppression of Hole Overflow and Enhancement of Light Emission Efficiency in Si Quantum Dots based Silicon Nitride Light Emitting Diodes, IEEE J Sel. Topics Quantum. Electron. 20 (2014) 8200306.

[11] R. Huang, K. Chen, B. Qian, S. Chen, W. Li, J. Xu, Z. Ma and X. Huang, Oxygen induced strong green light emission from low-temperature grown amorphous silicon nitride films, Appl. Phys. Lett. 89 (2006) 221120-221120-3.

[12] X. Wang, R. Huang, C. Song, Y. Guo, and J. Song, Effect of barrier layers on electroluminescence from $\mathrm{Si} / \mathrm{SiO}_{\mathrm{x}} \mathrm{N}_{\mathrm{y}}$ multilayer structures, Appl. Phys. Lett. 102 (2013) 081114.

[13] P. Zhang, K. Chen, H. Dong, P. Zhang, Z. Fang, W. Li, J. Xu, X. Huang, Higher than $60 \%$ internal quantum efficiency of photoluminescence from amorphous silicon oxynitride thin films at wavelength of 470 nm, Appl. Phys. Lett. 105 (2014) 011113.

[14] Z. Lin, R. Huang, Y. Guo, C. Song, Z. Lin, Y. Zhang, X. Wang, J. Song, H. Li and X. Huang, Near-infrared light emission from Si-rich oxynitride nanostructures, 
Opt. Mater. Express. 4 (2014) 816.

[15] J Wang, V Suendo, A Abramov, L Yu, P R i Cabarrocas, Strongly enhanced tunable photoluminescence in polymorphous silicon carbon thin films via excitation-transfer mechanism. Appl. Phys. Lett. 22 (2010) 221113-221113-3.

[16] A. Pérez-Rodriguez, O. Gonzalez-Varona, B. Garrido, P. Pellegrino, J. R. Morante, C. Bonafos, M. Carrada, A. Claverie, White luminescence from $\mathrm{Si}^{+}$and $\mathrm{C}^{+}$ ion-implanted $\mathrm{SiO}_{2}$ films, J. Appl. Phys. 94 (2003) 254-262.

[17] Y. Ding, H. Shirai, D. He, White light emission and electrical properties of silicon oxycarbide-based metal-oxide-semiconductor diode, Thin Solid Films. 519 (2011) 2513.

[18] S. Y. Seo, J. H. Shin, Enhancement of the green, visible $\mathrm{Tb}^{3+}$ luminescence from Tb-doped silicon-rich silicon oxide by C co-doping, Appl. Phys. Lett. 84 (2004) 4379-4381.

[19] S. Boninelli, G. Bellocchi, G. Franzò, M. Miritello, F. Iacona, New strategies to improve the luminescence efficiency of Eu ions embedded in Si-based matrices, J. Appl. Phys. 113 (2013) 143503.

[20] S. Gallis, M. Huang, A. E. Kaloyeros, Efficient energy transfer from silicon oxycarbide matrix to Er ions via indirect excitation mechanisms, Appl. Phys. Lett. 90 (2007) 161914-161914-3.

[21] Z. Lin, Y. Guo, C. Song, J. Song, X. Wang, Y. Zhang, R. Huang. Influence of the oxygen content in obtaining tunable and strong photoluminescence from low-temperature grown silicon oxycarbide films, J. Alloys Compd. 633 (2015) 
153-156.

[22] C. Song, R. Huang, X. Wang, Y. Guo, J. Song, Y. Zhang, Z. Zheng, Effects of hydrogen on photoluminescence properties of $\mathrm{a}-\mathrm{SiN}_{\mathrm{x}}: \mathrm{H}$ films prepared by VHF-PECVD, Appl. Surf. Sci. 258 (2011) 1290.

[23] R. Huang, Z. Lin, Y. Guo, C. Song, X. Wang, H. Lin, L. Xu, J. Song and H. Li, Bright red, orange-yellow and white switching photoluminescence from silicon oxynitride films with fast decay dynamics, Opt. Mater. Express. 4 (2014) 205.

[24] P. Pellegrino, A. Perez-Rodriguez, B. Garrido, O. Gonzalez-Varona, J. R. Morante, S. Marcinkevicius, A. Galeckas, J. Linnros, Time-resolved analysis of the white photoluminescence from $\mathrm{SiO}_{2}$ films after $\mathrm{Si}$ and $\mathrm{C}$ coimplantation, Appl. Phys. Lett. 84 (2004) 25-27.

[25] V. Nikas, S. Gallis, M. Huang, A. E. Kaloyeros, A. P. D. Nguyen, A. Stesmans, V. V. Afanasev, The origin of white luminescence from silicon oxycarbide thin films. Appl. Phys. Lett. 104 (2014) 061906.

[26] G. R. Lin, C. J. Lin, K. C. Yu, Time-resolved photoluminescence and capacitance-voltage analysis of the neutral vacancy defect in silicon implanted $\mathrm{SiO}_{2}$ on silicon substrate, J. Appl. Phys. 96 (2004) 3025.

[27] A. Grill, Plasma enhanced chemical vapor deposited SiCOH dielectrics: from low-k to extreme low-k interconnect materials, J. Appl. Phys. 93 (2003) 1785-1790.

[28] R. Huang, X. Wang, J. Song, Y. Guo, H. Ding, D. Wang, J. Xu, K. Chen, Strong orange-red light emissions from amorphous silicon nitride films grown at high pressures, Scripta Mater. 62 (2010) 643-645. 
[29] A. Grill, D. A. Neumayer, Structure of low dielectric constant to extreme low dielectric constant SiCOH films: Fourier transform infrared spectroscopy characterization, J. Appl. Phys. 94 (2003) 6697-6707.

[30] S. Gallis, M. Huang, H. Efstathiadis, E. Eisenbraun, A. Kaloyeros, E. Nyein, U. Hommerich, Photoluminescence in erbium doped amorphous silicon oxycarbide thin films, Appl. Phys. Lett. 87 (2005) 091901-091901-3.

[31] G. Bellocchi, F. Iacona, M. Miritello, T. Cesca and G. Franzò, SiOC thin films: an efficient light source and an ideal host matrix for $\mathrm{Eu}^{2+}$ ions, Opt. Express. 21 (2013) 20280.

[32] L. Skuja. Optically active oxygen-deficiency-related centers in amorphous silicon dioxide. J. Non-Cryst. Solids, 239 (1998) 16-48. 
Table caption

TABLE I. The integrated intensity and the full wide at half of maximum (FWHM) of the decomposed blue and orange Gaussian bands for $\mathrm{a}-\mathrm{SiC}_{\mathrm{x}} \mathrm{O}_{\mathrm{y}}$ films annealed at different temperatures.

\section{Figure captions}

Fig. 1. PL spectra of silicon oxycarbide samples annealed at different temperatures.

The spectra were deconvoluted into a strong blue Gaussian band and a weak orange

Gaussian band. The inset shows a photo of the sample annealed at $600{ }^{\circ} \mathrm{C}$ emitting light following excitation at $325 \mathrm{~nm}$ from a Xe lamp.

Fig. 2. Optical band gap and PL peak energy of the deconvoluted bands in a- $\mathrm{SiO}_{x} \mathrm{C}_{y}$ as a function of annealing temperature. Inset shows the Tauc plot of the as-deposited sample.

Fig. 3. The cross-sectional high-resolution TEM image of the sample annealed at $700{ }^{\circ} \mathrm{C}$.

Fig. 4. PL peak energy versus the excitation wavelength for the samples: (a) As-deposited sample, (b) the sample annealed at $500{ }^{\circ} \mathrm{C}$, (c) the sample annealed at $600{ }^{\circ} \mathrm{C},(\mathrm{d})$ the sample annealed at $700^{\circ} \mathrm{C}$. 
Fig. 5. Blue PL decay traces of the as-deposited sample and the samples annealed at $500{ }^{\circ} \mathrm{C}$ and $600{ }^{\circ} \mathrm{C}$, respectively. The decay traces fit the double exponential decay function: $\mathrm{I}(\mathrm{t})=\mathrm{I}_{0}+\underline{\mathrm{I}}_{1} * \exp \left(-\mathrm{t} / \tau_{1} \underline{)+\mathrm{I}_{2}} \underline{2}_{2} * \exp \left(-\mathrm{t} / \underline{\tau}_{2}\right)\right.$, where $\underline{\mathrm{I}}_{0} \underline{\text { is }}$ the background level, $\mathrm{I}_{\underline{i}}$ and $\tau_{\mathrm{i}}(\mathrm{i}=1,2)$ are the amplitude and lifetime of each exponential decay component, respectively [23].

Fig. 6. FTIR spectra of the as-deposited and annealed samples.

Fig. 7. Orange PL decay traces of the sample annealed at $700^{\circ} \mathrm{C}$. 


\begin{tabular}{c|cc|cc}
\hline \multirow{2}{*}{\multicolumn{1}{c|}{ Samples }} & \multicolumn{2}{c|}{ Blue } & band & \multicolumn{2}{c}{ Orange } & band \\
\cline { 2 - 5 } & $\begin{array}{c}\mathrm{I}_{\mathrm{PL}} \\
\text { (a.u.) }\end{array}$ & $\begin{array}{c}\text { PL spectrum } \\
\text { FWHM (nm) }\end{array}$ & $\begin{array}{c}\mathrm{I}_{\mathrm{PL}} \\
\text { (a.u.) }\end{array}$ & $\begin{array}{c}\text { PL spectrum } \\
\text { FWHM (nm) }\end{array}$ \\
\hline As-deposited sample & $2.2 \times 10^{7}$ & 129 & $2.0 \times 10^{7}$ & 166 \\
\hline Annealing at $500^{\circ} \mathrm{C}$ & $4.2 \times 10^{7}$ & 75 & $5.4 \times 10^{7}$ & 199 \\
\hline Annealing at $600^{\circ} \mathrm{C}$ & $4.5 \times 10^{7}$ & 77 & $6.9 \times 10^{7}$ & 196 \\
\hline Annealing at $700^{\circ} \mathrm{C}$ & $\ldots$ & $\ldots$ & $3.6 \times 10^{7}$ & 190 \\
\hline \hline
\end{tabular}

TABLE I

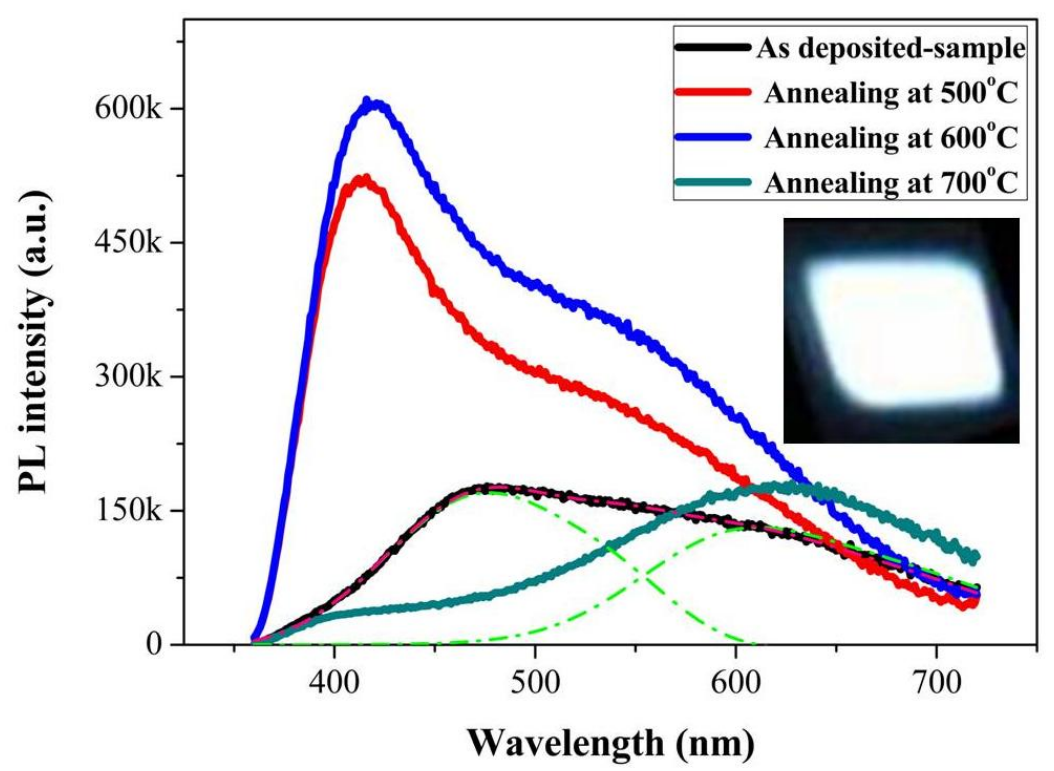

Fig. 1 


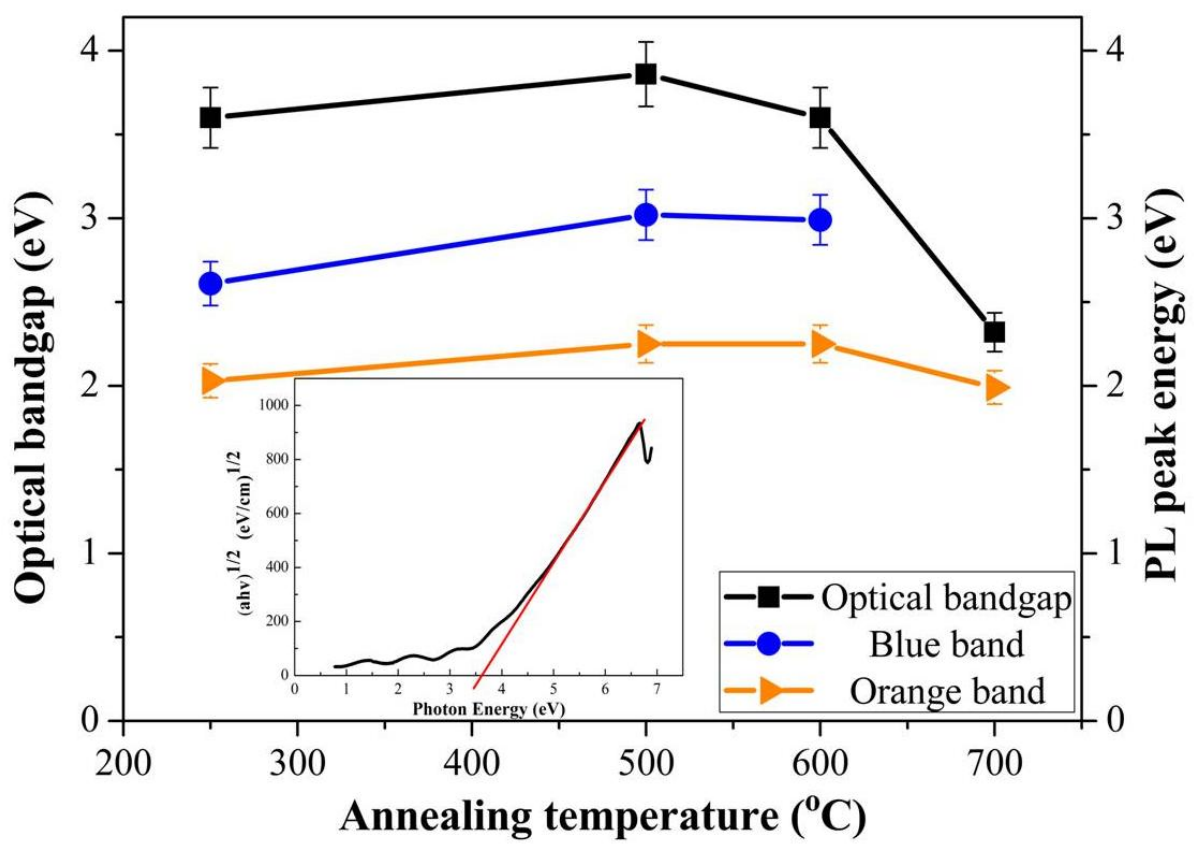

Fig. 2

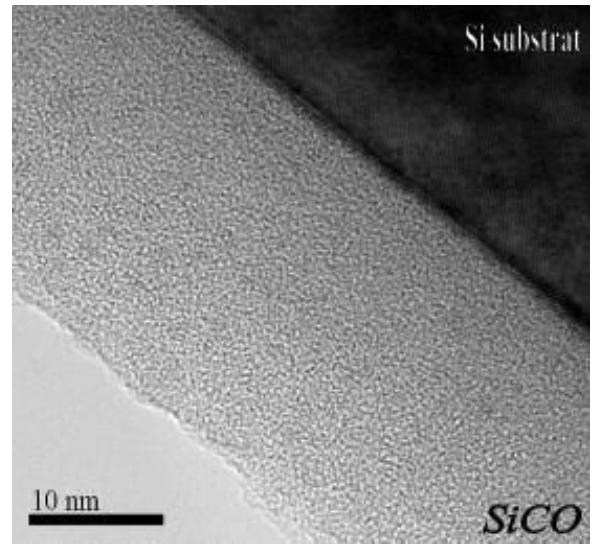

Fig. 3 

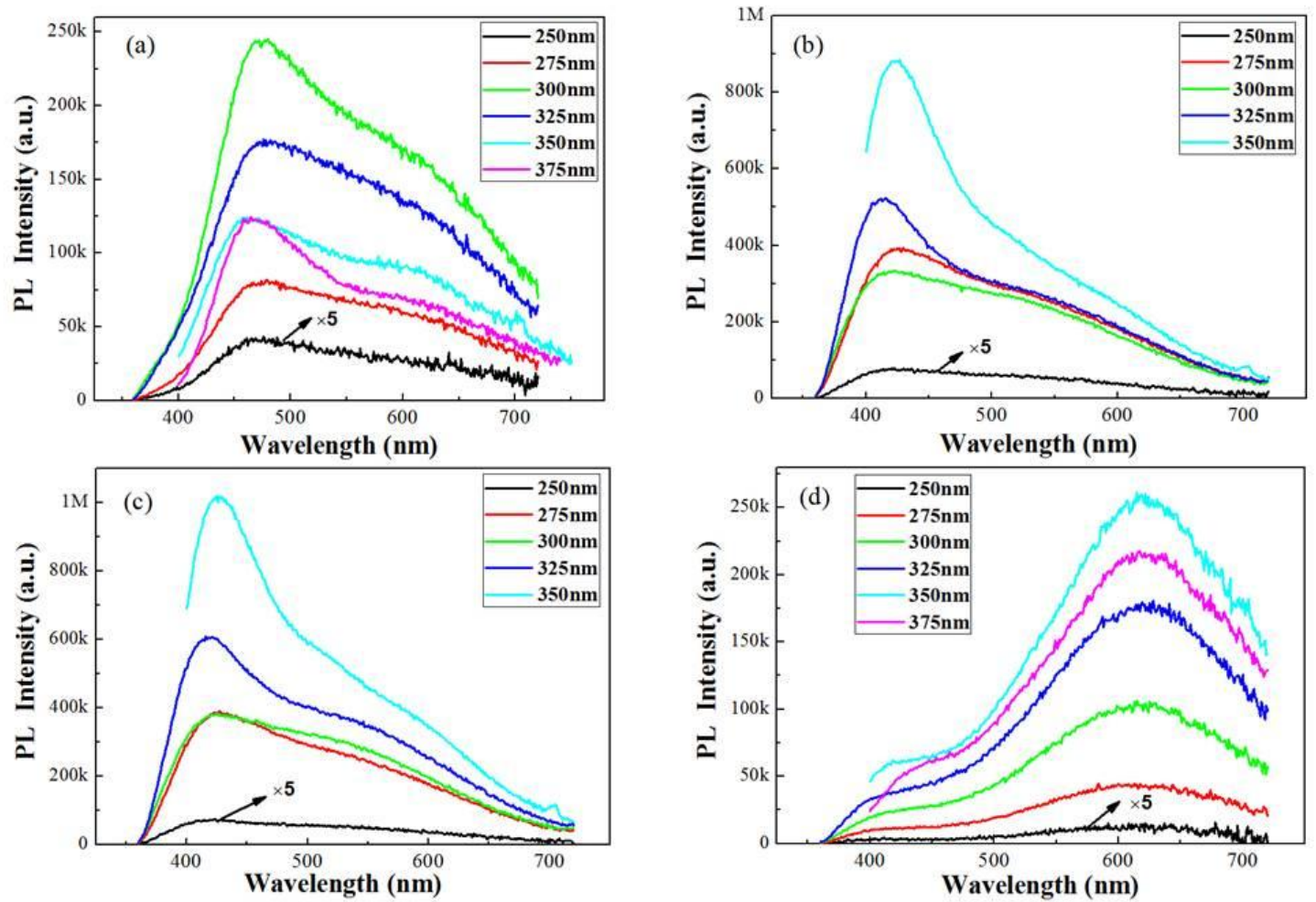

Fig. 4

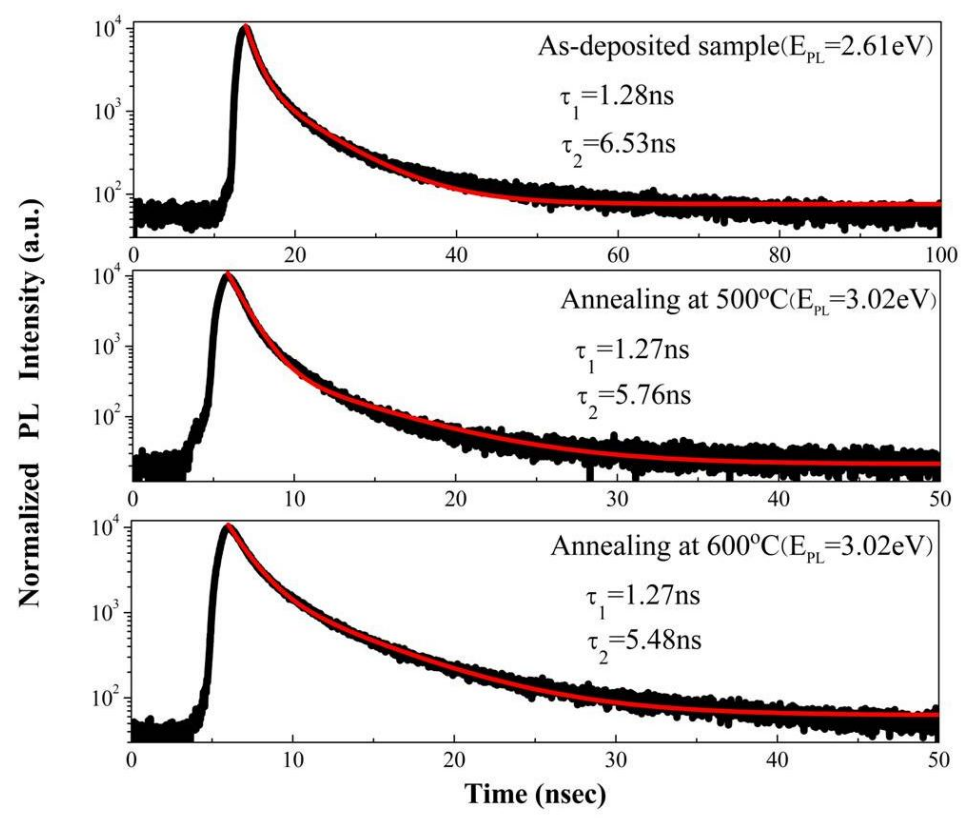

Fig. 5 


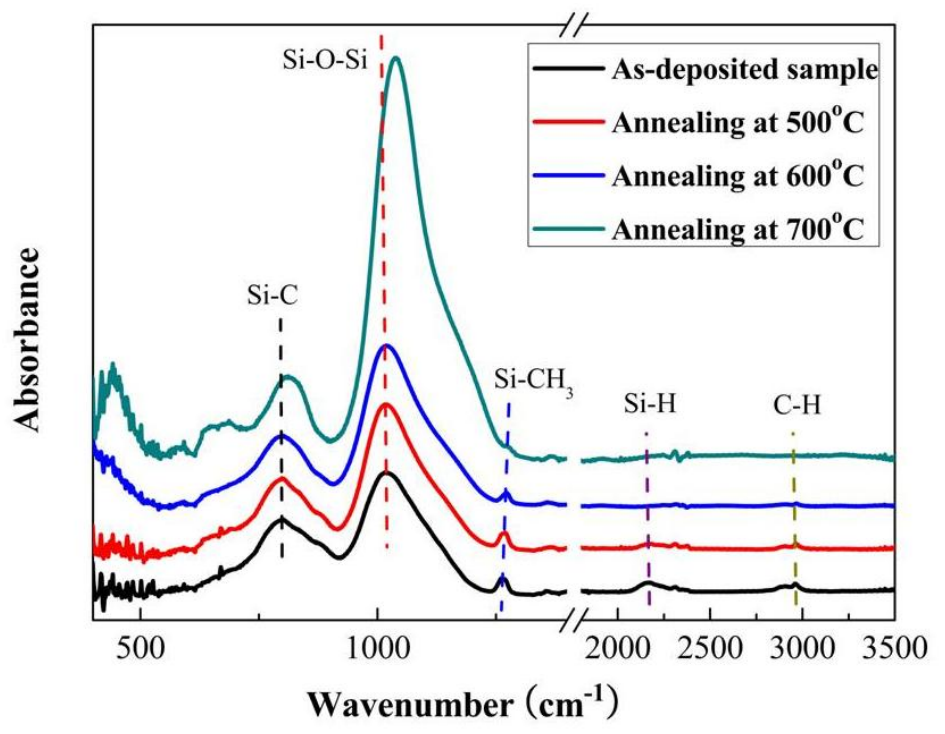

Fig. 6

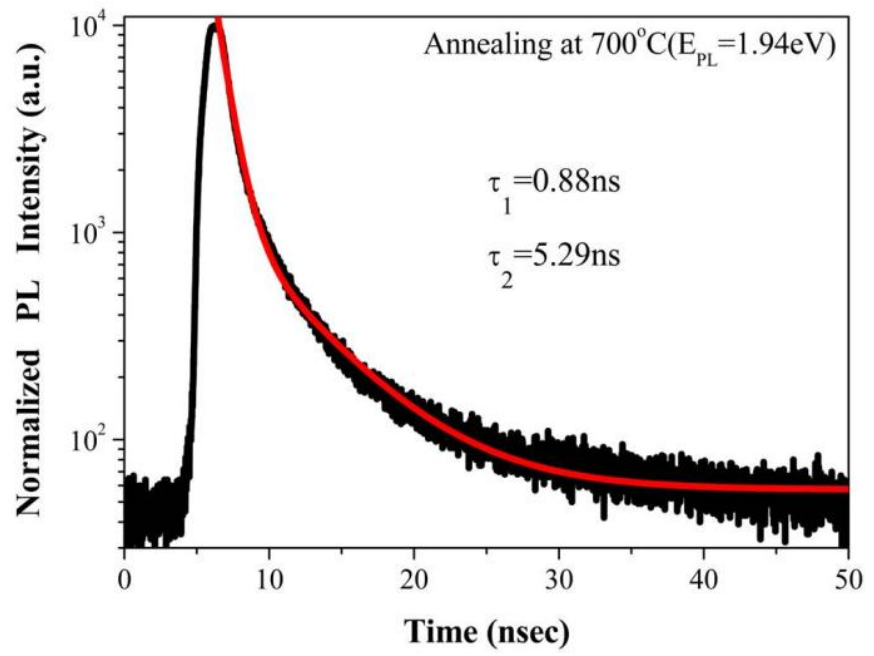

Fig. 7 